\title{
Study on the Top Ten Obstacles to the Development of Private Pension Institutions
}

\author{
Jun Wang \\ Schlool of Literature, Law and Economics \\ Wuhan University of Science and Technology \\ Wuhan, China
}

\begin{abstract}
Private pension institutions develop rapidly; however, obstacles during the development are also very obvious. At present, the development of private pension institutions has many obstacles such as unapparent effects of government support policies, difficulties of obtaining funds, inefficient human resources management, and poor effects of organizations daily management, harsh competition environment, operation difficulties, unclear positioning, the low trustworthiness and undefined property positions as well as coordination difficulties. In view of the obstacles above, the paper puts forward the corresponding countermeasures from both internal and external angles to promote the rapid development of private pension institutions.
\end{abstract}

Keywords-private pension institutions; ten obstacles; research

\section{INTRODUCTION}

In 2015 , the number of population aged 60 and above reached 22.2 million, accounting for $16.15 \%$ of the total. It is estimated that by 2020 , the elderly population will reach 248 million and the aging will reach $17.17 \%$. Among them, the population aged over 80 will reach 30.67 million. The growth of supporting the old has accelerated since 2000, and will increases to $16.9 \%$ by 2020 . The pension targets of "13th Five-Year Plan" are "the full coverage of day care in urban community, and the coverage rate reaching over $50 \%$ in rural, per thousand old people should have 35 to 45 beds," which is to say, by 2020, the number of Chinese pension beds should achieve 800 million or more. However, the current domestic situation is that per thousand elderly people have about 26 pension beds, the coverage rate of day care in urban community is $70 \%$, and $37 \%$ in rural, lacking more than 200 million pension beds. As supplementary pension institutions, private pension institutions, to a certain extent, relieve the pressure of public pension institutions. However, there are still lots of obstacles in the development of private pension institutions.

\section{TEN BARRIERS TO THE DEVELOPMENT OF PRIVATE PENSION INSTITUTIONS}

\section{A. Barriers to Government Support Policies}

1) The formulation of government support policies is not practical: In 2009, "Collection documents of Beijing giving social forces to build pension service institutions in order to build funds supporting pilot units " mentioned that the eligible pension institutions set up by social forces, the government will give one-time construction financial support in accordance with the types of pension institutions and construction methods: each bed of new and extended nursing care pension institutions will receive the funding of 16,000 yuan, and each bed of the non-nursing care pension institutions will receive the funding of 13,000 yuan; each bed of the nursing care pension institutions transformed by other facilities will receive the funding of 10,000 yuan, and each bed of the non-nursing care pension institutions will receive the funding of 8,000 yuan. The requirements of the policyholders are that land of the institutions must belong to themselves, but few private pension institutions can meet the conditions, the policy coverage rate is very low, basically losing the effectiveness of the policies. In 2016, Wuhan enacted the policy that per bed in the private pension institutions can obtain subsidies of 3,000 yuan; for some start-up private pension institutions, the subsidies made no sense, but for some mature institutions, the subsidies helped a lot. However, subsidies policy only took effect to a certain extent, while the effect is not high.

2) The implementation of government support policy is difficult: The support policies about private support agencies are according to the unified documents issued by the Ministry of Civil Affairs, local policies are different based on the local economic development and pension industry development, and the amount of subsidies and discount rates are also very different, in some areas, taxes are reduced, but construction and operating subsidies have been not issued.[1] At the same time, subsidies are different due to different institutional ownership and distinction, and the amount of subsidies and its use lack investigation. For the land of private support agencies, houses of most private 
non-profit pension institutions are leased, and they are faced with the problems of urban transformation, government planning and so on, causing many difficulties in using land, besides, the long vetting process and tedious procedures also impeded private support agencies' usage of land.

3) The assessment of government support policy is not comprehensive: The policies about private pension institutions introduced earlier, various regions also constantly introduced the corresponding support policies. Policy assessment is lack of profound studies, and there is bare of very comprehensive policy assessment program. Some policies are not perfect in the early development, resulting in the difficult implementation, and the policy implementation is even more impossible. Policy assessment, including various aspects such as policy formulation, policy implementation, policy feedback, plays a pivotal role in the effective implementation of supporting policies.

4) The supervision of government support policy is not timely: At present, the supervision subject of government support policy still is the government, and whether the subsidy policy is implemented is decided by the government. The unicity of the supervision subject and the lack of supervision system led to the tardy supervision of government on support policy. Many private pension institutions report that the government subsidies are not in place or still in the distribution, and the delay in arriving in the pension agency accounts seriously affects the operations of pension Institutions.

\section{B. Financial Barriers}

1) The inflows of social capital are insufficient: The government has been encouraging private capital to participate in the operation of private pension institutions. But the private pension institutions have the strong nature of social welfare and are non-profit, and its investment is large and earning cycle is very long, resulting in the phenomena that uncompetitive investors cannot invest, competitive investors dare not invest, and social capital inflows are seriously inadequate.

2) The use of funds is not scientific: Expenditure on private pension institutions mainly includes infrastructure, human resources, water and electricity gas, medical equipment, institutional land and so on. Institutional managers are easy to ignore the input of human resources and the purchase of medical equipment, which also results in the phenomenon of shortage of labor and difficulties of keeping staff in private pension institutions, low quality of service is also nothing to be surprised at. At the same time, institutional managers have lower cost awareness and lack saving awareness in fixed costs.

3) Loan conditions are harsh: Banks are the main way to finance private pension institutions, because most of the land used by private pension institutions is rented, so the lack of corresponding guarantees, the banking sector is reluctant to carry out its credit business. In the terms of the conditions for loan, the bank is very harsh.

\section{Human Resource Management Barriers}

1) The shortage of managers and care workers: Most of the private pension institutions have no professional management personnel, the majority of pension institutions openers are non-social workers, so the operation and management of pension institutions are in a very basic stage, for it can only guarantee that the elderly stay there. At present, care workers in most of private pension institutions need to take care of more than 10 old people at the same time, which serious reduced the service quality of the pension institutions, and elderly people also often expressed dissatisfaction. Care workers are in short supply.

2) The quality of staff is generally not high: Most private care workers in private pension institutions are middle and aged women in rural areas, who do not understand any care-related expertise, and their health conditions vary greatly. According to the survey, the proportion of private pension institutions managers holding bachelor's degree or above is very low, less than $20 \%$, which is a great obstacle to improving the operating efficiency of pension institutions.

3) Staff mobility is too large: The main reasons for the large mobility of employees include that salary is unsatisfactory and psychological needs are difficult to meet. On the one hand, in private pension institutions, the salary of care workers is very low, much less than the wages of traditional care workers. Naturally, it is difficult to retain employees. On the other hand, people that the staff get in touch with mainly are the elderly, the uncertainty of old people's physical conditions and the single work are also the reasons of large staff mobility. [2]

4) The rights and interests of employees is difficult to guarantee: The rights and interests of employees in private pension institutions cannot compare with those of public pension institutions. Staff of the public pension institutions that established by government are more stable, and their relevant rights and interests are also guaranteed. However, salary of employees in private pension institutions are low, it is difficult for them to enjoy insurance and housing fund and other benefits. At the same time, the development of pension institutions registered as private non-enterprise units are difficult; naturally, the rights and interests of employees are full of uncertainty.

\section{Institutional Management Barriers}

1) Low quality of service: Private pension institutions are in the initial development, and the service providing for the elderly is also very basic, mainly to meet basic physiological needs of the elderly, for instance, accommodation. The coverage of combination of medical treatment and nursing service is very low, most pension institutions do not have the conditions to purchase medical equipment, and individual medical institutions combined 
with nursing service have very limited beds, difficult to provide medical services. At the same time, due to limited activities and funds provided by the organizations, spare time life of the elderly is very boring.

2) Location is not user-friendly: Affected by urban transformation and the cost, private pension institutions have to be built in relatively remote areas. This way, medical treatment of the elderly and children's visit are not easy, and living quality of the elderly is difficult to guarantee. Therefore, the location of the pension institutions has a certain impact on the living quality of the elderly.

3) Poor infrastructure: According to the survey, most of the private pension institutions lack air conditioning and other infrastructure equipment, let alone the provision of fitness equipment for the elderly's spare time life. [3] Private pension institutions only have the simplest beds as well as tables and chairs, and some institutions only get fans installed in rooms, which result in sunstroke happened on the elderly occasionally.

\section{E. Competition Barriers}

1) There is a lot of pressure to compete with public pension institutions: As is well known, public pension institutions is significantly different with private pension institutions in the aspects of service content, land nature, facility location, year established, government policy, occupancy rate, which decide that private pension institutions is difficult to compete with public pension institutions, causing the public pension institution appears that "a spare bed is difficult to find" and occupancy rate of private pension institutions is low.

2) Competitive pressure is high in the same area: The competition is becoming increasingly fierce among private pension institutions in the same area. Governments are constantly supporting the development of private pension institutions, vigorously subsidizing private pension institutions, and the number of private pension institutions is rising perpendicularly. Some institutions with poor facilities, high fees and low service quality will be eliminated.

3) Competitive pressure is high in different areas: The differences between private pension institutions in different regions are remarkable. The private pension institutions in some developed cities like Beijing, Shanghai and Guangzhou have started early, and the economy has developed faster. The government attaches great importance to support private pension institutions, and the development of private pension institutions is in a good condition, while some private pension institutions in developing cities are still in the early stage, and the development gap is very wide.

\section{F. Positioning Barriers}

1) Positioning of institutional individual function is not clear: The private pension institutions are not clear on functional localization, and they just provide similar service as others without widening the differences in service quality. Just a few institutions recommend that the combination of medical treatment and nursing service; most institutions are undefined to functional localization, but only provide the most common pension service, which is not conducive to the development of the pension institutions.

2) There are no strict functional divisions in regions: At present, types of the elderly staying in the private pension institutions almost all includes completely self-care, semiself-self-care, and unable to self-care.[4] Although there are some differences in the charges, in fact living of the elderly are in a mixed state without appropriate nursing staff or complete corresponding equipment, and the organization has no clear functional tendencies.

\section{G. Operational Barriers}

1) Pricing is unreasonable: Unreasonable pricing of private pension institutions is mainly reflected in the high price. The source of income of most private pension institutions are mainly from payment of the elderly, while the expense of private pension institutions are far greater than the income, making institutions have to raise charges to improve their income so as to maintain the normal operation of the organization, which also resulting in a decrease in occupancy rate.

2) Income channel is single: Private pension institutions' income are very single, mainly from payment of the elderly, and institutional managers do not open up other income channels in the process of operating the agencies, in the meantime, institutional operating costs are relatively fixed, all this leading to further expansion of operational pressure.

3) Long-term profit-free is difficult to sustainable development: At present, the number of retired private pension institutions is also increasing year by year for the cost of investment is large and capital returns slowly.[5] Many institutions make ends meet, and most of the small private pension institutions are in the red, only a very small number of institutions having meager profits. Long-term to maintaining the state, it is difficult to have sustained and stable capital income and it is completely impossible for institutions to scale up or improve the service quality, more difficult to sustainable development.

\section{H. Trust Barriers}

1) The trust between the elderly and the institutions is low: Influenced by traditional ideas, the elderly and children always lack trust on private pension institutions.[6] In their eyes, private pension institutions have higher charges, poorer facilities, lower service quality, and they even cannot compare with public pension institutions. Identification degree of old people on pension institutions is not high, coupled with currently bad situation of private pension institutions, resulting in a lot of elderly people prefer to live alone than staying in pension institutions, which conduce to a low occupancy rate of private pension institutions.

2) The trust between institutions and the government is low: The government lacks standardized management of the development of private pension institutions, and the 
coherence in policies are poor. Supportive policies are always unimplemented, and some preferential policies are only "literal policies"; private pension institutions lack trust on the government, and the two sides are difficult to coordinate with each other, being difficult to promote the development of institutions.

\section{Property Rights Barriers}

Private pension institutions mainly refer to the pension institutions that are established by private persons and have independent legal personality after the registration of civil affairs departments as well as carry out non-profit social welfare activities. In other words, private pension institutions are non-profit and public beneficial, but the private pension institutions are the product of the market economy and the important supplement and support to public pension institutions. Without purpose of but need to make profit, private pension institutions improve service quality and scale up by profit making. The profit of the pension institutions registered as private non-enterprise units shall not be used for dividends, which makes it difficult to use market means to strengthen their own development. The property rights of private pension institutions do not belong to individuals, and individuals cannot get the dividend of profit, which make investors flinch.

\section{J. Coordination Barriers}

1) It lacks coordination between private pension institutions and public pension institutions: In recent years, the services of public pension institutions has gradually covered all the old, and mainly turned to provide services for the vulnerable groups in older people such as the old people with dementia and the disabled elders. However, the service groups of private pension institutions also include all types of the elderly, and the lack of coordination between the two kinds of pension institutions led to a serious overlap in the scope of business; public pension institutions have natural competitive advantages, which hinder the development of private pension institutions.

2) It lacks coordination between the private pension institutions and the government: The government lacks a unified and coordinated planning of the private pension institutions leading to the non-standardized development of the private pension institutions. Although the number of private pension institutions has increased significantly, the development quality is low, services contents are basic, and the mode are single. Therefore, it is difficult to form a complete system of social services for the elderly with public pension institutions.

\section{COUNTERMEASURES TO BREAK THE BARRIERS TO DEVELOPMENT OF PRIVATE PENSION INSTITUTIONS}

\section{A. External Aspects of the Institutions}

1) All policies should be fully implemented and the necessary basic guarantees should be provided: The government should make unified planning for the development of private pension institutions such as annual goal of the number of beds and the old people enrolled, and the development goal of private pension institutions in all regions must be planned ahead. First of all, the government should start from the formulation of supportive policies, conduct in-depth investigation and research on private pension institutions to formulate accurate supportive policies in order to ensure the scientificness and effectiveness of supportive policy formulation. Secondly, when supporting policies are implemented, other departments should band with civil affairs departments to promptly track progress in the implementation of policies to change the traditional inspection mechanism for the dynamic monitoring mechanism. Finally, after the implementation of the policy, an assessment should be carried out to establish a multi-level evaluation system. According to the feedback and investigation by private institutions, the ineffective policies should be modified and the theoretical system of supporting policies should be constantly improved and optimized with the development of private pension institutions.

2) Laws, regulations and policies should be improved to promote orderly development of institutions: On November 20, 2015, General Office of the State Council transmitted "Guidance on Promoting the Combination of Health Care and Pension Services" and fully deployed the plan to further promote the combination of health care and pension services, basically establish and form service network of the combination of medical treatment and endowment system, and policies and laws by 2020. The government is in the stage of overall planning for the formulation of the laws and regulations on pension institutions. It should issue detailed legal provisions in the examination and approval, operation and evaluation of private pension institutions; at the same time, the local governments, while increasing the support strength for private pension institutions, should refer to central regulations to formulate special development plans of institutions and supplemented relevant legal provisions, which include the further refinement of the management system for pension institutions, the human resources management system, the health and fire management system, and the standardization and normalization of service functions.[7] Also, the government should further improve the financial subsidies and tax policies, increase financial subsidies for private pension institutions year by year to expand the scope of tax breaks, give appropriate subsidies to pension insurance institutions, and keep more liberal policies on land using as well as establish and improve supporting facilities.

3) Superior resources of the government should be integrated, and the development of multi-type institutions should be supported: At present, the quantity demand of beds in private pension institutions in China is hard to meet, while the occupancy rate of private pension institutions is very low, which is essentially an manifestation of the unmet 
effective demand of the elderly. The needs of the elderly include the three aspects of daily care, medical care, and emotional sustenance. However, private pension institutions generally provide the most basic daily care, causing that the high-level needs of the elderly are difficult to meet. Therefore, the functional configuration of pension institutions is particularly important. The function of the organization should be diversified and featured services should be provided, for example, the features of Taikang nursing home are the comfortable living environment and good medical services, which attract a large number of elderly people. The government should actively support the development of various types of pension institutions, [5] such as the private pension institutions built by the government and the private pension institutions with the combination of medical treatment and endowment, to help private pension institutions develop well while meeting the residential needs of the elderly.

4) Volunteer service groups are actively formed to share the pressure on the operation of pension institutions: Volunteer service groups should be actively formed in universities and various social organizations to regularly carry out service activities for entering the pension institutions and to learn from volunteer activities in developed areas such as Hong Kong. Firstly, volunteer service groups should attract a large number of volunteers to join volunteer organizations, including elite students and teachers in colleges and universities as well as social elites. Secondly, a unified management system of volunteer agencies should be established, and volunteers should be arranged to participate in some work of nursing workers in private pension institutions; besides, basic nursing knowledge training before work should be carried out to offer more professional services to the elderly in private pension institutions, and to give a more professional volunteer experience to volunteers. It can not only share the operating pressure of pension institutions, but also benefit volunteers. Finally, private pension institutions should have a long-term cooperation with volunteer service groups to deliver volunteers to private pension institutions regularly to carry out their services and popularize the work of volunteers participating in the service of private pension institutions across the country to maximize the value.

5) Trade associations have a role to play in guiding the healthy development of pension services: Private pension institutions associations should be established in all regions, including all levels of provinces, cities and counties. The private pension institutions have spontaneously set up and hold meetings regularly to study the problems arising in the development of the institutions and help the government solve the development difficulties of private pension institutions. At the same time, the function of the association should be further refined. An industry selfdiscipline mechanism should be established by the associations to improve overall industry quality and protect the rights and interests of their members and overall interests of the industry according to law; to participate in the formulation of the national development plan for the aging industries, and give advice to government authorities on industrial policies and economic legislation; to cooperate with government departments in carrying out relevant occupational skills appraisal and assessment of serving the old; and to organize the recognition of the selection in industry. Besides, information network of aging industries should be established, industry publications should be compiled in accordance with the regulations, and all kinds of training for employees should be organized.

\section{B. Internal Aspects of the Institutions}

1) Publicity campaign should be carried out to raise public awareness for pension institutions: The main reasons that the elderly are not willing to live in private pension institutions are that they do not understand the development of private pension institutions. Their understanding of private pension institutions is only based on self-perception and hearsay. Carrying out a series of publicity activities is beneficial to help the elderly fully understand private pension institutions and spread advanced conception on public pension, which is of great help to improve the occupancy rate of private pension institutions. First, the continuity of publicity campaign should be paid attention to. This is also a problem that many organizations have in running promotions. They gave wide publicity since the establishment of the organizations, but have no promotion in the future days, which is hard to work. Second, the authenticity of promotional information should be guaranteed. In order to attract more senior citizens, many private pension institutions operators lower their prices intentionally and claim the best service. As soon as the old check in, it's found that there is a long way to go before the operators commit themselves. As a result, there are conflicts between the elderly and the institutions.

2) The service mode should be innovated to upgrade the market competitiveness of the organization: At present, the service modes of many China's private pension institutions are out-dated, being uncompetitive compared with the public pension institutions; therefore, it is particularly urgent to innovate the service modes of private pension institutions. First of all, the service mode of private pension institutions in developed countries (such as Japan) can be learned; for example, the private pension institution in Japan called Happy Family is full of humanity, which reflected in the aspects of location, accommodation design, catering hygiene, hospice care and so on. Secondly, the institutions can combine with its own advantages to develop various services with its own characteristics. For example, Wuhan Shumei Nursing Home attaches great importance to the health of the elderly, and their food therapy of herb medicine has been unanimously approved by the elderly and their families. Finally, the quality of basic services should 
be paid attention to while the institutions innovating services. Managers of pension institutions often neglect basic nursing work in the pursuit of innovation, which lead to the living quality of the elderly cannot be guaranteed, making it hard to retain the elderly and the sustainable development of the institutions.

3) Establishing a human resources mechanism to alleviate the shortage of professionals: Establish a scientific human resources management system, including personnel recruitment system, staff training and development system, performance appraisal system, salary system, labor relations system. First, broadening the recruitment channels and improving recruitment conditions, the government can require the relevant colleges and universities to set up related majors and courses; [8] establish co-cultivation of personnel programs, and jointly carry out the summer social practice activities with colleges and universities to enhance graduates' awareness of pension institutions and arouse their interest in the endowment cause. Second, performing training demand analysis and participating in training courses of other organizations (such as associations) actively, in the meantime, the institutions should carry out training courses regularly to enhance the professional competence of staff and the ability to adapt to the sustainable development of the institutions, as well as provide exchange learning opportunities in private pension institutions in the developed areas for staff to improve the staff qualities comprehensively. Third, establishing a KPI performance appraisal system to improve the enthusiasm of the staff and work out a salary system based on the performance appraisal results to ensure the fairness of the system. Fourth, protecting the basic rights and interests of employees includes the signing of the labor contract and the payment of five insurance, and giving appropriate material or spiritual incentives to improve the satisfaction of employees.

4) Establishing a cooperation mechanism and promoting the combination of medical treatment and endowment vigorously: The combination of medical treatment and endowment is the growing trend of private pension institutions advocated by the government. It is also necessary for private pension institutions' sustainable development. More and more old people and their relatives set the medical treatment level of pension institutions as the primary reference for whether to stay or not, so it is extremely urgent to establish newly private pension institutions with the combination of medical treatment and endowment. First of all, in the location of private pension institutions, the residual land of hospitals should be taken into account. Using the residual land of and the land adjacent to hospitals to construct pension institutions can solve the problem of low coverage of medical security at the greatest extent. Second, the institutions should cooperate with hospitals to hold consultations at regular intervals. This also is the measure taken in the remote areas in China at present in order to monitor the physical condition of the elderly effectively and take steps promptly. Finally, for private pension institutions with better economic conditions, medical teams should be set up within the institutions to solve the emergency situation of the elderly promptly and organize regular medical examination.

5) Broadening the operational ideas to realize institutional operating profit: First: establishing programming committee of the elderly to train an elderly performing troupe. In recent years, the atmosphere of learning to dance for the elderly is getting stronger and the elderly all over the country spontaneously learn to dance. Pension institutions can employ relevant dance teachers to give guidance, train a team of elders with performing ability to participate in the performance for weddings and funerals in towns to gain benefits. It not only enriches amateur life of the old, but also makes profits for the institutions. Second: improving medical level of institutions to provide medicines and basic medical services for the elderly. Many elderly people suffer from chronic diseases such as hypertension, diabetes, etc., and they generally choose long-term medication to control the diseases. Pension institutions should communicate with the elderly and their families actively and provide the elderly with the medicines they need as well as dock with hospitals to provide convenience for the elderly on the basis of making proper profit. At the same time, the institutions should provide emergency medical services for the elderly based on charging appropriately. Third: Giving full play to the specialties of the elderly and benefit jointly with the institutions. People of different times have different skills and many old people own unique skills. Managers of the institutions should fully understand the old living here, discover the specialties of the elderly and transform them into business value. Some seniors are able to do traditional food such as rice dumplings and sugar, which can be sold by institution employees. In this way, both the elderly and the institutions can get benefit from the selling realizing a win-win situation.

\section{CONCLUSION}

There are many obstacles in the development of private pension institutions. The paper proposes the top ten obstacles including that the inconspicuous effect of government support policies, access to funds is difficult, low management efficiency of human resources, poor effect of daily management of institutions, harsh competitive environment, great difficulties in operation, unclear positioning of institutions, low trust, unclear positioning of property rights, coordination difficulties and so on. The obstacles proposed in the article basically contain all difficulties in the development of private pension institutions, having strong scientificity and pertinence. Meanwhile, the paper put forward the corresponding solutions from both inside and outside of the institution, which are highly operable and can break the corresponding obstacles to some extent. It also provides some theoretical bases for the research on private pension institutions. 


\section{REFERENCES}

[1] Restrictions of and Countermeasures to the Development of Private Pension Institutions - A Case Study of Yongzhou, Hunan [J]. Journal of Hunan First Normal College, 2016,16 (4): 97-102.

[2] Qian Xuefei. Research on the Development of Private Pension Institutions in the Perspective of Standardization - An Empirical Analysis Based on 100 Private Pension Institutions in Nantong, Jiangsu [J]. Journal of Nantong Textile Vocational Technology college, 2016,16 (3): 35-40.

[3] Chen Airu, Zhang Jie. Study on the Development Path of Private Pension Institutions - Based on the Field Survey of 9 Institutions in Anhui Province [J]. Journal of Changchun University of Science and Technology, 2015,28 (6): 56-61.

[4] Fan Xiying. Effectiveness and optimization of private pension institutions in China in the perspective of human capital [J]. Shenzhen University Journal, 2013,30 (6): 159-163.

[5] Yao Shuxue. Analysis on Problems and Causes of Shenyang private pension institutions [J]. Marketing Research, 2015.12.

[6] Zhu Hao. Research on the Development Model of Private Pension Institutions Based on Trust - A Case Study of Hangzhou [J]. Scientific Research on Aging, 2014,2 (11): 26-35.

[7] Li Rong. Operating Conditions and Development Strategy of Private pension institutions - Taking Hangzhou as an example [J]. Space of Business Management Journal , 2015,8.

[8] Hu Yankun, Zhang Guocheng, Zhou Yun. Difficulties and Solutions of Security-style private pension institutions in Wuhan [J]. Pioneering With Science \& Technology Monthly, 2016 (22). 